\title{
Journal metrics of Clinical and Molecular Hepatology based on the Web of Science Core Collection
}

\author{
Sun Huh
}

Department of Parasitology and Institute of Medical Education, Hallym University College of Medicine, Chuncheon, Korea

Background/Aims: Eight years have passed since Clinical and Molecular Hepatology changed its language policy to English-only in September 2010. The journal has been included in PubMed Central since September 2010. Present title continues the Korean Journal of Hepatology since June 2012. It has been indexed in the Web of Science Core Collection as an Emerging Sources Citation Index journal since 2015. I sought to determine whether the change in language policy was successful based on journal metrics. I also investigated whether the journal has become one of the top-ranked world journals in the category of gastroenterology and hepatology.

Methods: The following journal metrics were calculated or analyzed based on the journal's bibliographic information from 2012 to 2017 and the Web of Science Core Collection database: citable and non-citable articles, country of authors, total cites, impact factor, the immediacy index, country of citing authors, citing journal titles, and the Hirsch index.

Results: From 2012 to 2017, there were 282 citable articles. Authors from 29 countries have published in the journal. The number of total citations in 2017 was 611. The impact factor increased from 2.1 in 2014 to 2.8 in 2017. The citing authors were from 85 countries, and their papers have been cited in 663 journals. The Hirsch index was 19.

Conclusions: Based on journal metrics, Clinical and Molecular Hepatology has succeeded in becoming a top-ranked international journal 8 years after changing its language policy to English-only. (Clin Mol Hepatol 2018;24:137-143)

Keywords: Bibliometrics; Editorial policies; Open access publishing; Statistics

Study Highlights

Clinical and Molecular Hepatology has been indexed in the Web of Science Core Collecton since 2015. From 2012 to 2017, authors of Clinical and Molecular Hepatology were from 29 countries. Its calculated impact factor increased from 2.1 in 2014 to 2.8 in 2017 . Base on the journal metrics, Clinical and Molecular Hepatology was promoted to top-notch international journal.

\section{Abbreviations:}

ORCID, Open Researcher and Contributor ID; XML, Extensible Markup Language

\author{
Corresponding author : Sun Huh \\ Department of Parasitology and Institute of Medical Education, Hallym \\ University College of Medicine, 1 Hallymdaehak-gil, Chuncheon 24252, \\ Korea \\ Tel: +82-33-248-2652, Fax: +82-33-241-1672 \\ E-mail:shuh@hallym.ac.kr \\ http://orcid.org/0000-0002-8559-8640
}

Received : Feb. 20, 2018/ Revised : Mar. 30, 2018/ Accepted : May 21, 2018

Copyright $\odot 2018$ by Korean Association for the Study of the Liver

This is an Open Access article distributed under the terms of the Creative Commons Attribution Non-Commercial License (http://creativecommons.org/licenses/by-nc/3.0/) which permits unrestricted non-commercial use, distribution, and reproduction in any medium, provided the original work is properly cited. 


\section{INTRODUCTION}

How can we measure a scholarly journal's influence in the worldwide network of journals? Journal metrics, which are bibliometric indicators of a journal's performance, are a measurement tool for this purpose. Journal metrics include a variety of indicators, such as total cites, impact factor, immediacy index, cited/citing half-life, the Eigen factor, and the article influence score based on the Web of Science Core Collection ${ }^{\circledR}$. Of these indicators, total cites and the impact factors are popular indicators that are easy to understand.

Clinical and Molecular Hepatology is the official journal of Korean Association for the Study of the Liver. It launched in 1995 as the Korean Journal of Hepatology. It was indexed in MEDLINE starting with Volume 8, Number 1, March 2002. In June 2012, its title was changed to Clinical and Molecular Hepatology. An English-only language policy was adopted since September 2010. It has been also indexed in Scopus since 2002 as a MEDLINE sourced journal. Full text Extensible Markup Language (XML) has been deposited in PubMed Central since September 2010. It has been indexed in the Web of Science Core Collection as an Emerging Sources Citation Index journal since 2015. Eight years have passed since the language policy change in 2010. Its inclusion in these citation databases makes it easy to calculate a variety of journal metrics, making it possible to understand its position and influence in the worldwide journal network.

In this special article, I would like to analyze the journal metrics of Clinical and Molecular Hepatology based on Web of Science Core Collection. Such an analysis may elucidate the position of the journal objectively. I hypothesized that Clinical and Molecular Hepatology has become an internationally top-ranked journal. Specifically, citable and non-citable articles, country of authors, total cites, impact factor, the immediacy index, country of citing authors, citing journal titles, and the Hirsch index were analyzed.

\section{MATERIALS AND METHODS}

\section{Study design}

This was a descriptive analysis based on a literature database.

\section{Materials}

The journal that was analyzed was Clinical and Molecular Hepa- tology (since June 2012). The Web of Science Core Collection maintained by Clarivate Analytics was searched as source data. The literature search was done on February 18, 2018.

\section{Journal metrics}

Journal metrics used in this study was same to previous researches. ${ }^{2}$ Terms were briefly described as below.

Citable and non-citable articles: Original articles, reviews, case reports, information on liver pathology, liver images, and "Clinical and Molecular Hepatology material published elsewhere" were counted as citable articles, while editorial materials, errata, corrections, letters were treated as non-citable articles. To calculate the impact factor, non-citable articles were eliminated from the denominator.

Country of authors: Authors of the journal articles were analyzed based on their country of affiliation.

Total cites: This refers to the number of citations in a given year.

Impact factor: The 2-year impact factor was calculated according to the following formula, in which the 2017 impact factor is used as an example:

2017 impact factor:

Number of citable articles in the journal in 2015: A

Number of citable articles in the journal in 2016: B

Number of citations of articles from the journal published in 2015 in the Web of Science Core Collection in 2017: C

Number of citations of articles from the journal published in 2016 in the Web of Science Core Collection in 2017: D

\section{7 impact factor $=(C+D) /(A+B)$}

The 2-year impact factor can be interpreted as a measurement of the speed of evolution of the journal. If the content of any category changes rapidly, and its volume increases quickly, the 2-year impact factor will show a higher value than more slowlyevolving categories.

Immediacy index: This is calculated by dividing the number of citations to articles published in a given year by the number of articles published in that year. It indicates how quickly articles in a journal are cited. High immediacy index means rapidly evolving content.

Country of citing authors: This refers to the country of affiliation of the authors citing the journal. It shows the extent to 
which the journal is used throughout the world.

Citing journal titles: These are the titles of the journals that published the articles citing the journal being analyzed.

Hirsch index: A scientist is defined as having a Hirsch index of $h$ "if $h$ of his or her $N_{p}$ papers have at least $h$ citations each and the other $\left(N_{p}-h\right)$ papers have $\leq h$ citations each". ${ }^{3}$ This definition can be extended to journals. Frequently cited articles were sorted by citation frequency and classified by publication type. In Table 1, when number of citation is equal to or more than ranking number, the ranking number is the Hirsch index of the journal.

Statistical analysis: Data were presented by descriptive statistics.

Table 1. Most frequently cited articles in Clinical and Molecular Hepatology according to publication type from 2012 to 2017

\begin{tabular}{|c|c|c|c|c|c|c|c|}
\hline No. & Year & Volume & Issue & Page & Article title & $\begin{array}{l}\text { Number of } \\
\text { citations }\end{array}$ & $\begin{array}{l}\text { Publication } \\
\text { type }\end{array}$ \\
\hline 1 & 2013 & 19 & 3 & 210 & $\begin{array}{l}\text { Nonalcoholic fatty liver disease: molecular mechanisms for the } \\
\text { hepatic steatosis }\end{array}$ & 89 & Review \\
\hline 2 & 2012 & 18 & 2 & 109 & $\begin{array}{l}\text { KASL Clinical Practice Guidelines: Management of chronic } \\
\text { hepatitis B }\end{array}$ & 63 & Review (guideline) \\
\hline 3 & 2016 & 22 & 1 & 7 & $\begin{array}{l}\text { A concise review of updated guidelines regarding the } \\
\text { management of hepatocellular carcinoma around the world: } \\
\text { 2010-2016 }\end{array}$ & 48 & Review (guideline) \\
\hline 4 & 2012 & 18 & 2 & 163 & Clinical applications of transient elastography & 43 & Review \\
\hline 5 & 2012 & 18 & 3 & 249 & Drug-induced liver injury: present and future & 42 & Review \\
\hline 6 & 2013 & 19 & 1 & 17 & Hepatitis C virus: virology and life cycle & 38 & Review \\
\hline 7 & 2012 & 18 & 4 & 347 & Hepatitis C virus and hepatocarcinogenesis & 37 & Review \\
\hline 8 & 2012 & 18 & 4 & 337 & $\begin{array}{l}\text { The role of gut-liver axis in the pathogenesis of liver cirrhosis and } \\
\text { portal hypertension }\end{array}$ & 34 & Review \\
\hline 9 & 2015 & 21 & 2 & 105 & Hepatitis C virus-induced hepatocellular carcinoma & 32 & Review \\
\hline 10 & 2013 & 19 & 2 & 105 & $\begin{array}{l}\text { Important predictor of mortality in patients with end-stage liver } \\
\text { disease }\end{array}$ & 30 & Review \\
\hline 11 & 2012 & 18 & 3 & 258 & $\begin{array}{l}\text { Changes of guidelines diagnosing hepatocellular carcinoma } \\
\text { during the last ten-year period }\end{array}$ & 28 & Review (guideline) \\
\hline 12 & 2013 & 19 & 1 & 1 & Hepatitis C virus: virology and life cycle & 28 & Review \\
\hline 13 & 2014 & 20 & 4 & 327 & Cost-of-illness studies: concepts, scopes, and methods & 27 & Review \\
\hline 14 & 2013 & 19 & 4 & 349 & Acute-on-chronic liver failure & 26 & Review \\
\hline 15 & 2013 & 19 & 2 & 156 & $\begin{array}{l}\text { The usefulness of transient elastography, acoustic-radiation- } \\
\text { force impulse elastography, and real-time elastography for the } \\
\text { evaluation of liver fibrosis }\end{array}$ & 23 & Original article \\
\hline 16 & 2014 & 20 & 1 & 6 & $\begin{array}{l}\text { Hepatic venous pressure gradient: clinical use in chronic liver } \\
\text { disease }\end{array}$ & 21 & Review \\
\hline 17 & 2013 & 19 & 2 & 99 & $\begin{array}{l}\text { The lymphatic vascular system in liver diseases: its role in ascites } \\
\text { formation }\end{array}$ & 20 & Review \\
\hline 18 & 2013 & 19 & 4 & 370 & $\begin{array}{l}\text { The usefulness of non-invasive liver stiffness measurements in } \\
\text { predicting clinically significant portal hypertension in cirrhotic } \\
\text { patients: Korean data }\end{array}$ & 20 & Original article \\
\hline 19 & 2015 & 21 & 3 & 220 & The mutational landscape of hepatocellular carcinoma & 20 & Review \\
\hline 20 & 2014 & 20 & 1 & 61 & $\begin{array}{l}\text { Radiofrequency ablation of very-early-stage hepatocellular } \\
\text { carcinoma inconspicuous on fusion imaging with B-mode US: } \\
\text { value of fusion imaging with contrast-enhanced US }\end{array}$ & 19 & Original article \\
\hline
\end{tabular}




\section{RESULTS}

Citable and non-citable articles were presented in Fig. 1. Of the 282 citable articles from 2012 to 2017, 127 (45.4\%) were original articles, 64 (22.1\%) were reviews, 49 were cases (27.4\%), and 40 were pathology and images (14.9\%). Number of non-citable articles was 31.

The countries of authors from 2012 to 2017 for both citable and non-citable articles are presented in Fig. 2. The authors of 276 articles were from Korea; while those of 69 articles (22.1\%) were from outside of Korea. Authors from 28 countries outside of Korea have published in the journal, and the United States (23) and

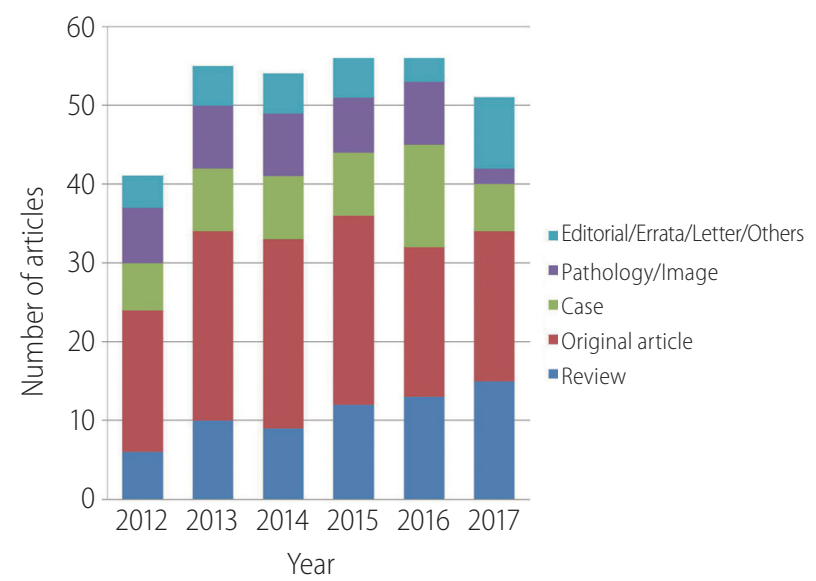

Figure 1. Publication type of articles in Clinical and Molecular Hepatology from 2012 to 2017. Citable articles include reviews, original articles, case reports, information on liver pathology, and liver images. Non-citable articles include editorials, letters, corrections, and Clinical and Molecular Hepatology material published elsewhere.

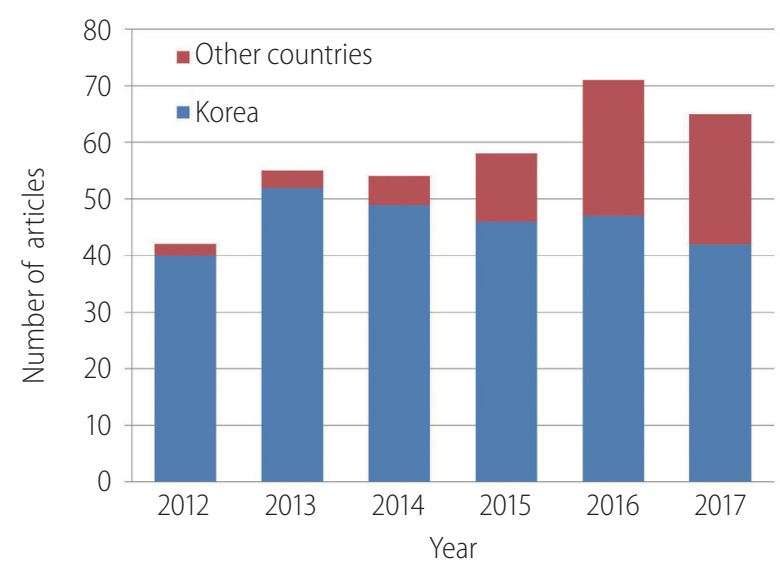

Figure 2. Number of articles from Korea and other countries in Clinical and Molecular Hepatology from 2012 to 2017.
China (7) were the countries with the most frequent publications (Fig. 3).

Total cites are presented in Fig. 4. The number of total cites for 2017 was 611.

The impact factor (2-year) is presented in Fig. 5. It soared from 2.115 in 2014 to 2.808 in 2017.

The immediacy index from 2012 to 2017 is presented in Fig. 6 . It increased from 0.027 in 2012 to 0.524 in 2017.

The countries of citing authors are presented in Fig. 7. Korea, China, and the United States were the top 3 countries of citing authors, out of the total of 85 countries.

Articles were cited in 663 journals. The titles of the top 11 journals that cited the journal most frequently are displayed in Fig. 8 . The total number of citations by the 652 other journals was 1,232. Journal self-citation rate was 3.3\% $(55 / 1,654)$.

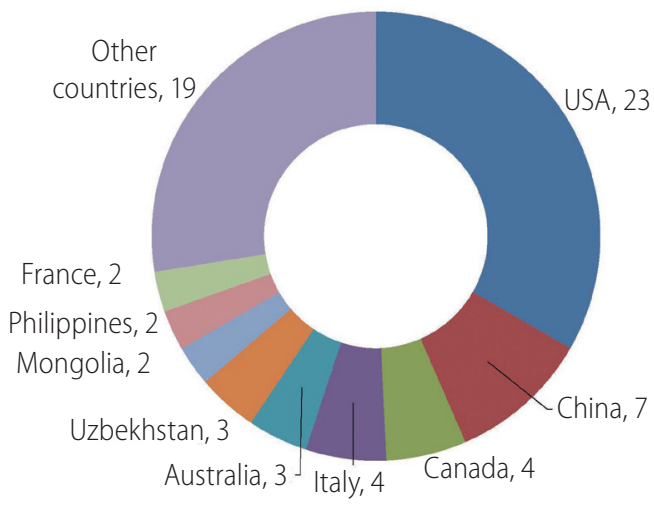

Figure 3. Distribution of author countries other than Korea in Clinical and Molecular Hepatology from 2012 to 2017. USA, United States of America.

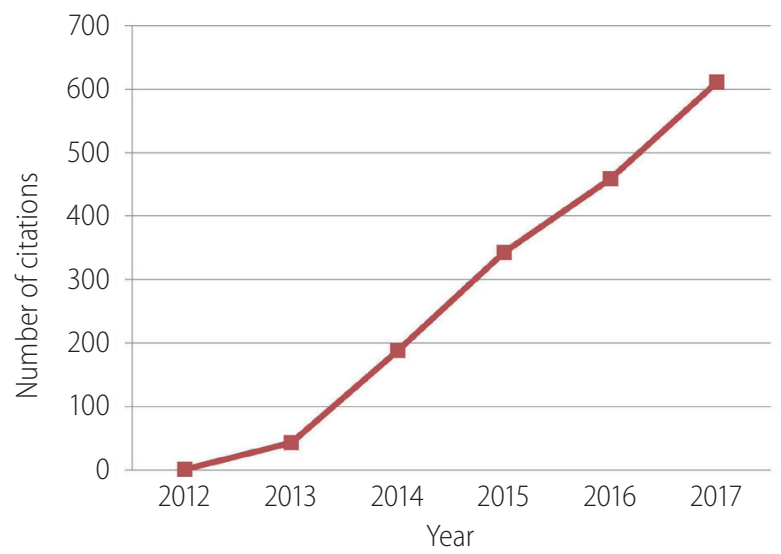

Figure 4. Changes in total citations to Clinical and Molecular Hepatology from 2012 to 2017. 
Hirsch index: Based on Table 1, which presents the most frequently cited articles of the journal published from 2012 to 2017, the Hirsch index was 19. Two of these 19 articles were original articles, while the other 17 were reviews. Three of these 17 review articles were on clinical guidelines.

\section{DISCUSSION}

Although the journal launched in 1995 as the Korean Journal of Hepatology, it began to be disseminated to international researchers and physicians in 2002 after being indexed in MEDLINE. Eight years after being indexed in MEDLINE, the change of the journal's language policy to English-only from a policy of accepting articles in Korean or English can be said to have succeeded in attracting

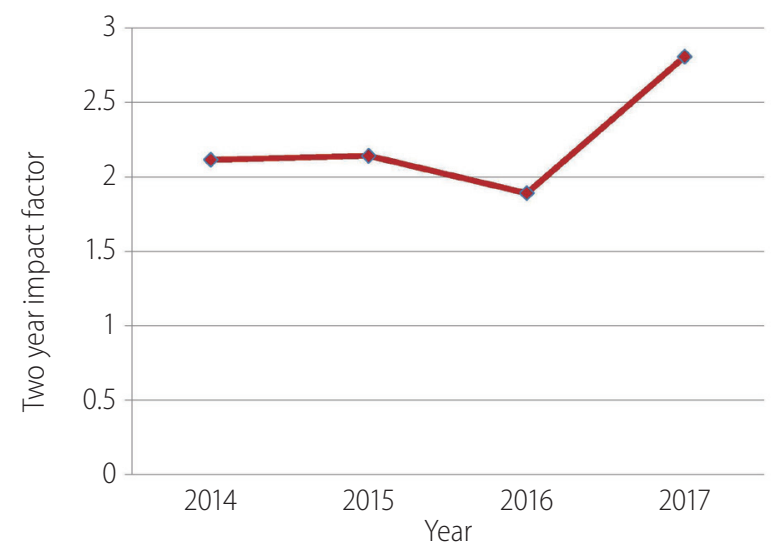

Figure 5. Changes in the 2-year impact factor of Clinical and Molecular Hepatology from 2014 to 2017.

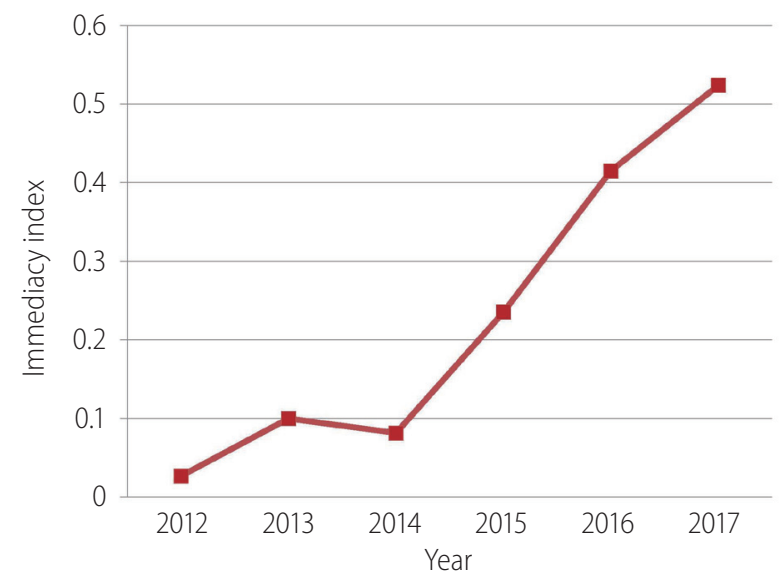

Figure 6. Changes in the immediacy index of Clinical and Molecular Hepatology from 2012 to 2017. the interest of researchers and physicians from throughout the world. It is not easy for the non-native English speakers to write in English for academic publication ${ }^{4}$; therefore, it is not an easy decision for the journal to adopt the English-only policy. It was successful in case of Clinical and Molecular Hepatology based on the above result.

Liver diseases were the eighth most common cause of death in Korea in 2016. ${ }^{5}$ The high prevalence of liver diseases and the high mortality associated with these conditions in the 1990s was the background for the launch of this specialized journal on liver diseases in Korea. Twenty-three years after the launch of the journal, it is evident that it has attracted authors and readers from all over the world. The turning point was the implementation of an English-only policy in September 2010. The number of articles by authors from outside Korea increased from 2 (4.8\%) in 2012 to 23

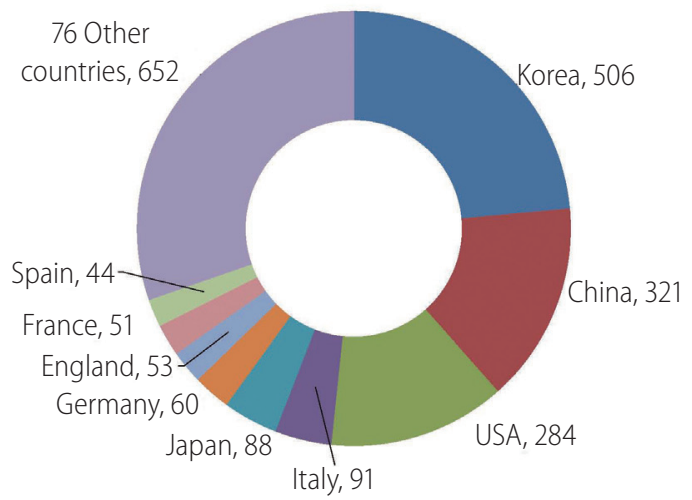

Figure 7. Countries of authors citing Clinical and Molecular Hepatology from 2012 to 2017. USA, United States of America.

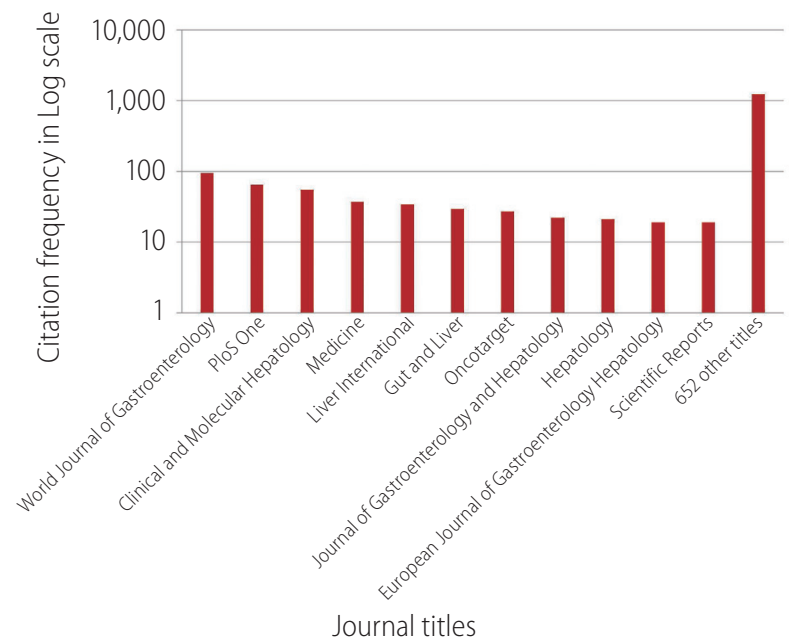

Figure 8. Titles of the top 11 journals that cited Clinical and Molecular Hepatology in articles published from 2012 to 2017. 
(35.4\%) in 2017 (Fig. 2). The authors were from 29 countries throughout this period. Fig. 3 showed the number of articles from 28 countries outside of Korea from 2012 to 2017. The increase of total cites from 1 in 2012 to 611 in 2017 was the most dramatic change for the journal's reputation (Fig. 4), although the number of citable articles from 2012 to 2017 was 282 (Fig. 1). The 2-year impact factor increased from 2.115 in 2014 to 2.808 in 2017, which corresponds to a ranking of 40th out of 79 journals in the recent 'gastroenterology and hepatology' Journal Citation Reports category available from: https://clarivate.com/products/journal-citation-reports/. The immediacy index also increased from 0.027 to 0.524 in 2017 (Fig. 6). This corresponds to a ranking of $31.6 \%$ in the same category.

As for the country of citing authors' affiliation, Korea, China, and the United States were the leading countries (Fig. 7). This means that the journal is publishing content of interest to researchers and physicians in those countries. The 85 countries of the authors who cited the journal are distributed all over the world, which means that the journal is valuable to hepatology researchers throughout the world. Fig. 8 presents the titles of the 11 journals that have most frequently cited this journal. The top 3 journal titles were World Journal of Gastroenterology (94 times), PLoS One (65), and Clinical and Molecular Hepatology (55). The self-citation rate of the journal was 0.03 . This journal has been cited 1,654 times by articles published in 663 journals.

The Hirsch index of the journal, 19, is a wonderful achievement by the journal during the past 6 years especially in comparison with the Hirsch index of other medical journals published in Korea: Clinical and Experimental Vaccine Research, 13 with 110 citable articles within 5 years of launching as an English-language journal'; Intestinal Research, 8 over 3 years with 136 citable articles $^{6}$; Journal of Exercise Rehabilitation, 7 over 4 years with 247 citable articles; ; Clinics in Orthopedic Surgery, 13 with 378 citable articles over 7 years ${ }^{8}$; Neurointervention, 7 with 72 citable articles over 5 years ${ }^{9}$; Journal of Educational Evaluation for Health Professions, 5 with 141 citable articles over 10 years ${ }^{10}$; Annals of Rehabilitation Medicine, 9 with 546 citable articles over 10 years ${ }^{11}$; Clinical Endoscopy, 6 with 318 citable articles over 4 years ${ }^{12}$; and Annals of Pediatric Endocrinology \& Metabolism, 7 with 208 citable articles over 6 years. ${ }^{13}$ Usually, reviews receive more citations than original articles or case reports. ${ }^{8,13}$ This was the case for Clinical and Molecular Hepatology as well. An interesting finding of this study is that 3 reviews dealing with clinical guidelines received especially many citations. Clinical guidelines are one of the most valuable forms of content for physicians; therefore, the chance to be cited may be high. Five review articles were cited more than 40 times. Review articles are usually invited by the editor. This means that the editor of the journal has selected appropriate topics for physicians and hepatology researchers and has recruited excellent authors to write about those topics. This confirms that the keen eye of the editor has contributed to the development of the journal's brand.

In addition to the excellent work of the editor, what has contributed to the development of Clinical and Molecular Hepatology into a top-level journal based on journal metrics? For the development of the journal's brand, 2 aspects should be considered. One is the value of the content itself, and the other is worldwide exposure through the internet. ${ }^{14}$ The former consideration requires a ceaseless effort to recruit high-quality manuscripts and to maintain the competency of journal by minimum requirements. However, the latter consideration is relatively easy to address. First, introducing digital standards for a scholarly journal is mandatory. ${ }^{15}$ Second, an open-access policy is essential for the journals of nonprofit societies. ${ }^{16,17}$ To compete with other branded and already well-established scholarly journals published by commercial publishing companies and large society journals in North America and Western Europe, the content of the journal should be provided to all researchers without hindrance. Clinical and Molecular Hepatology has already adopted an open-access policy and has done an excellent job of introducing and implementing digital standards, including journal article tag suite (JATS) XML ${ }^{18}$, digital object identifiers ${ }^{19}$, CrossRef cited-by linking, Check for Updates (CrossMark), Funder Registry (FundRef) ${ }^{20}$, text and data mining ${ }^{21}$, Open Researcher and Contributor ID (ORCID) ${ }^{22}$, and CrossRef similarity check (Crosscheck).

Furthermore, I suggest that the following measures be adopted for the further development of the journal. First, adopting an open-data policy will help guarantee the scientific soundness and replicability of the content. Journals with an open-data policy in Korea are rare, as only a few journals have adopted this policy. ${ }^{23}$ It was found that there was no difficulty in introducing this policy, as most authors can be expected to straightforwardly adhere to the journal's policy. ${ }^{24}$ Second, the introduction of author taxonomy is recommended. Author taxonomy is a description of each author's role in the article, such as conceptualization, data curation, formal analysis, funding acquisition, methodology, project administration, visualization, writing-original draft, and writingreview \& editing.

In conclusion, I can confirm that Clinical and Molecular Hepatology has become an internationally top-ranked journal 8 years af- 
ter adopting an English-only language policy, based on journal metrics such as the diversity of authors' countries, the 2-year impact factor, total cites, the immediacy index, the diversity of the countries of citing authors, and the Hirsch index. This was enabled by the editors' devotion to the journal and the society's unstinting support for publishing the journal. Liver disease is one of the leading causes of death and an important cause of morbidity not only in Korea, but also throughout the world. Therefore, I am certain that this journal will continue to devote itself to preventing liver diseases and saving human lives. The adoption of an opendata policy and an author taxonomy system will be the next steps to guarantee scientific soundness for readers and to verify authors' roles more specifically.

\section{Conflicts of Interest}

The author has no conflicts to disclose.

\section{REFERENCES}

1. Kim K, Chung Y. Overview of journal metrics. Science Editing 2018;5:16-20.

2. Huh S. Clinical and Experimental Vaccine Research's promotion to internationally competitive journal evidenced by journal metrics. Clin Exp Vaccine Res 2017;6:67-71.

3. Hirsch JE. An index to quantify an individual's scientific research output. Proc Natl Acad Sci U S A 2005;102:16569-16572.

4. Harbord J. Language policy and the disengagement of the international academic elite. Science Editing 2018;5:32-38.

5. Statistics Korea. Annual report on the cause of death statistics. Statistics Korea web site, <http://www.index.go.kr/potal/main/EachDtIPageDetail. do?idx_cd=1012>. Accessed 2018.02.18

6 . Jeong GH, Huh S. The great rise of Intestinal Research as an international journal 3 years after its language change to English as evidenced by journal metrics. Intest Res 2017;15:1-4.

7. Huh S. Promotion of the Journal of Exercise Rehabilitation to the international level based on journal metrics. J Exerc Rehabil 2016;12:510-514.

8. Huh S. Clinics in Orthopedic Surgery's evolution into an International
Journal Based on Journal Metrics. Clin Orthop Surg 2016;8:127-132.

9. Huh S. Promotion of Neurointervention to international journal based on journal metrics. Neurointervention 2016;11:5-9.

10. Huh S. How much is Journal of Educational Evaluation for Health Professions promoted based on journal metrics? J Educ Eval Health Prof 2015;12:57.

11. Huh S. The elevation of Annals of Rehabilitation Medicine to the status of an international journal after adopting an English-only policy. Ann Rehabil Med 2015;39:661-666.

12. Huh S. Evidence of the internationalization of Clinical Endoscopy based on journal metrics. Clin Endosc 2015;48:317-321.

13. Huh S. The rapid internationalization of Annals of Pediatric Endocrinology \& Metabolism as evidenced by journal metrics. Ann Pediatr Endocrinol Metab 2017;22:77-81.

14. Chi Y. Scientific publishing in the Asian century: an international perspective. Science Editing 2016;3:112-115.

15. Jeong GH, Huh S. Status of digital standards in Korean medical journals in 2016. Science Editing 2016;3:100-104.

16. Seo JW, Chung H, Seo TS, Jung Y, Hwang ES, Yun CH, et al. Equality, equity, and reality of open access on scholarly information. Science Editing 2017:4:58-69.

17. Kim K. Open access publishing in the internet age. Science Editing 2016;3:1-2.

18. Huh S. Coding practice of the Journal Article Tag Suite extensible markup language. Science Editing 2014;1:105-112.

19. Lammey R. CrossRef tools for small publishers. Science Editing 2015;2:79-85.

20. Lammey R. How to apply CrossMark and FundRef via CrossRef extensible markup language. Science Editing 2014;1:84-90.

21. Lammey R. CrossRef text and data mining services. Science Editing 2015;2:22-27.

22. Im J. Applying open researchers and contributors ID in scholarly journals. Science Editing 2015;2:28-31.

23. Huh S. Promotion to MEDLINE, indexing with Medical Subject Headings, and open data policy for the Journal of Educational Evaluation for Health Professions. J Educ Eval Health Prof 2016;13:14.

24. Huh S. Establishment of an open data policy for Journal of Educational Evaluation for Health Professions, appreciation for invited reviewers, and acknowledgement of volunteers who made audio recordings. J Educ Eval Health Prof 2017;14:37. 